\title{
FATIGUE STRENGTH OF ONESIDE-WELDED JOINT WITH BACKING STRIP
}

\author{
By Dong Uk LEE* and Kohsuke HORIKAWA**
}

\begin{abstract}
Angular distortion and misalignment are the typical initial imperfections of welded-joint in steel structure. Stress and strain concentration at the root and the toe of welded-joint become larger when the welded-joint has misalignment, as misalignment causes a moment with applied force. Therefore, fatigue strength of the welded-joint with misalignment is inferior to that without misalignment.

In this paper, fatigue strength of such joint was investigated using the specimen, which was scale-up model of a cross section of U-shape trough rib. Stress concentration factor of the root was analyzed by the finite-element method and was measured by static loading test. Cyclic loading test was carried out to clarify the effect of root shape on fatigue life and the relation between fatigue crack propagation rate and stress intensity factor range. Also, the effect of scale-up rate of the specimen was investigated.
\end{abstract}

\section{INTRODUCTION}

The angular distortion due to thermal cycle as well as misalignment owing to misfitting have been investigated as initial imperfections of welded-joint in steel structure ${ }^{1) \sim 4)}$. It is known that the stress concentration and the strain concentration occur at the root and the toe of welded-joint with angular distortion and misalignment as a moment occurs at the welded-joint with angular distortion and misalignment by applied force ${ }^{3) \sim 5}$. However, it is hard to avoid misalignments in field-welded joints of steel bridges. Oneside-welded joint with backing strip is often used for the field-welding of a closed U-shape trough rib. Stress flows are disturbed at the welded-joint with backing strip.

According to the results of bending fatigue test on the U-shape trough rib of full scale specimen and tensile fatigue test on specimen with backing strip, where in both cases the specimens included misalignment and weld defects ${ }^{6) .7)}$ :

1) The fatigue life was shorter as the misaligment became larger,

2) Even though several weld defects were involved in the fusion zone, they were not always crack initiation points,

3) The cracks of all specimens initiated from the root or the toe of welded-joint.

Even the welded-joints were fabricated with same materials and welding conditions, the shapes of the root had various types ${ }^{7}$. It has been known that fatigue life becomes longer when the toe of welded-joint becomes smooth.

This paper deals with stress concentration factor (SCF) and fatigue life of oneside-welded joint with

* Student Member of JSCE, Ms. Eng., Graduate student, Dept. of Welding Engineering, University of Osaka (Yamada-oka, Suita, Osaka 565).

** Member of JSCE, Dr Eng., Associate Professor of Osaka University (11-1, Mihoga-oka, Ibaraki, Osaka 567). 
backing strip. Specimen was scale-up model of a cross section of a U-shape trough rib with misalignment ${ }^{6.7)}$ . The root shapes are two types : one is right angle, and the other is semicircular. The SCF was analyzed by the finite-element method and was measured by static loading test. The cyclic loading test was carried out to investigate the effect of root shape on fatigue life and the relation between fatigue crack propagation rate and stress intensity factor range ${ }^{8) .9}$. Also, the effect of scale-up rate of the specimen was investigated.

\section{ANALYSIS BY FINITE-ELEMENT METHOD}

The models were same as experimental specimens which were scale-up models of a cross section of a $\mathrm{U}$-shape trough ribs with misalignment $(0,2$, and $4 \mathrm{~mm})$. Configurations and sizes of the specimens are shown in Fig. 1 and Table 1. The misalignment of the specimen A, B and C are 0, 2 and $4 \mathrm{~mm}$ respectively. The root shape of specimen B-5 R and C-5 R are semicircular and the others are right angle as shown in Fig. 1. The FEM mesh of each specimen is shown in Fig. 2. The hatched area R and T in Fig. 2 a) correspond to the root and the toe of welded-joint respectively. Fig. $2 \mathrm{~b} \sim \mathrm{h}$ ) indicate the root, and $\mathrm{i} \sim \mathrm{j}$ ) present the toe. The smallest element size, number of element and nodal point of each specimen are shown in Table 2. Nodal points with same coordinates are given individually for each side of contact surface between base metal and backing strip.

Principal stresses on the root and the toe of each specimen were shown in Fig. $2 \mathrm{~b} \sim \mathrm{j}$ ) when such external force was applied that nominal stress at parallel portion become unit $\left(1.0 \mathrm{~kg} / \mathrm{mm}^{2}\right)$. Accordingly, the principal stresses correspond to the stress concentration factors (SCF's). From this analysis:

1) The SCF was large at base metal side in the root of specimen with right angle, while the SCF was
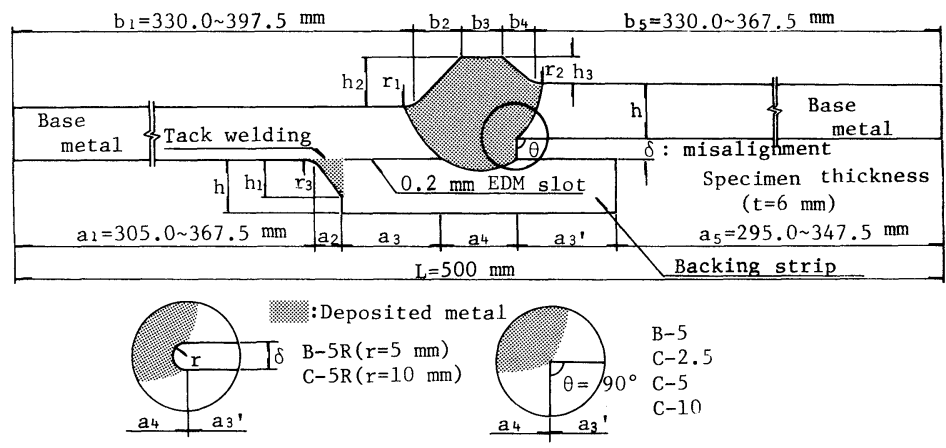

Fig. 1 Specimen configuration

Table 1 FEM model and test specimen size.

(Unit : mm)

\begin{tabular}{|c|c|c|c|c|c|c|c|c|c|c|c|c|c|c|c|}
\hline SP. & $\mathrm{a}_{2}$ & $\mathrm{a}_{3}$ & $a_{3}^{\prime}$ & $\mathrm{a}_{4}$ & $b_{2}$ & $b_{3}$ & $b_{4}$ & $h$ & $h_{1}$ & $h_{2}$ & $h_{3}$ & $r_{1}$ & $r_{2}$ & $r_{3}$ & $\delta$ \\
\hline $\begin{array}{l}A-5 \\
B-5 \\
B-5 R \\
C-2.5 \\
C-5 \\
C-5 R \\
C-10\end{array}$ & $\begin{array}{l}20.0 \\
20.0 \\
20.0 \\
10.0 \\
20.0 \\
20.0 \\
40.0\end{array}$ & $\begin{array}{l}55.0 \\
55.0 \\
55.0 \\
27.5 \\
55.0 \\
55.0 \\
55.0\end{array}$ & $\begin{array}{l}55.0 \\
55.0 \\
51.1 \\
27.5 \\
55.0 \\
47.2 \\
55.0\end{array}$ & $\begin{array}{l}40.0 \\
40.0 \\
43.9 \\
20.0 \\
40.0 \\
47.9 \\
40.0\end{array}$ & $\begin{array}{l}22.5 \\
25.0 \\
25.0 \\
11.3 \\
22.5 \\
22.5 \\
45.0\end{array}$ & $\begin{array}{l}25.0 \\
25.0 \\
25.0 \\
12.5 \\
25.0 \\
25.0 \\
50.0\end{array}$ & $\begin{array}{l}22.5 \\
20.0 \\
20.0 \\
11.3 \\
22.5 \\
22.5 \\
45.0\end{array}$ & $\begin{array}{l}30.0 \\
30.0 \\
30.0 \\
15.0 \\
30.0 \\
30.0 \\
60.0\end{array}$ & $\begin{array}{l}20.0 \\
20.0 \\
20.0 \\
10.0 \\
20.0 \\
20.0 \\
40.0\end{array}$ & $\begin{array}{l}15.0 \\
25.0 \\
25.0 \\
15.0 \\
30.0 \\
30.0 \\
60.0\end{array}$ & $\begin{array}{r}15.0 \\
15.0 \\
15.0 \\
5.0 \\
10.0 \\
10.0 \\
20.0\end{array}$ & $\begin{array}{r}20.0 \\
20.0 \\
20.0 \\
20.0 \\
2.5 \\
20.0 \\
0\end{array}$ & $\begin{array}{c}20.0 \\
20.0 \\
20.0 \\
20.0 \\
10.0 \\
20.0 \\
0\end{array}$ & $\begin{array}{r}20.0 \\
20.0 \\
20.0 \\
10.0 \\
2.5 \\
20.0 \\
0\end{array}$ & $\begin{array}{c}0 \\
10.0 \\
10.0 \\
10.0 \\
20.0 \\
20.0 \\
40.0\end{array}$ \\
\hline
\end{tabular}

Table 2 The smallest element size, number of elements

and nodal points on each specimen.

\begin{tabular}{l|rrrrrrrrr}
\hline Specimen & A-5 & B-5 & B-5R & C-2.5 & C-5 & C-5R & C-10 & C-5R(T) & C-10(T) \\
\hline S.EL.S & 1.0 & 1.0 & 1.0 & 1.0 & 1.0 & 1.0 & 1.0 & 1.0 & 1.0 \\
Element & 330 & 392 & 392 & 323 & 376 & 379 & 391 & 297 & 346 \\
N.Point & 204 & 234 & 238 & 208 & 226 & 230 & 238 & 194 & 215 \\
\hline
\end{tabular}

S.EL.S : Smallest Element Size (mm)

Element: Number of Elements

N.Point: Number of Nodal Points 

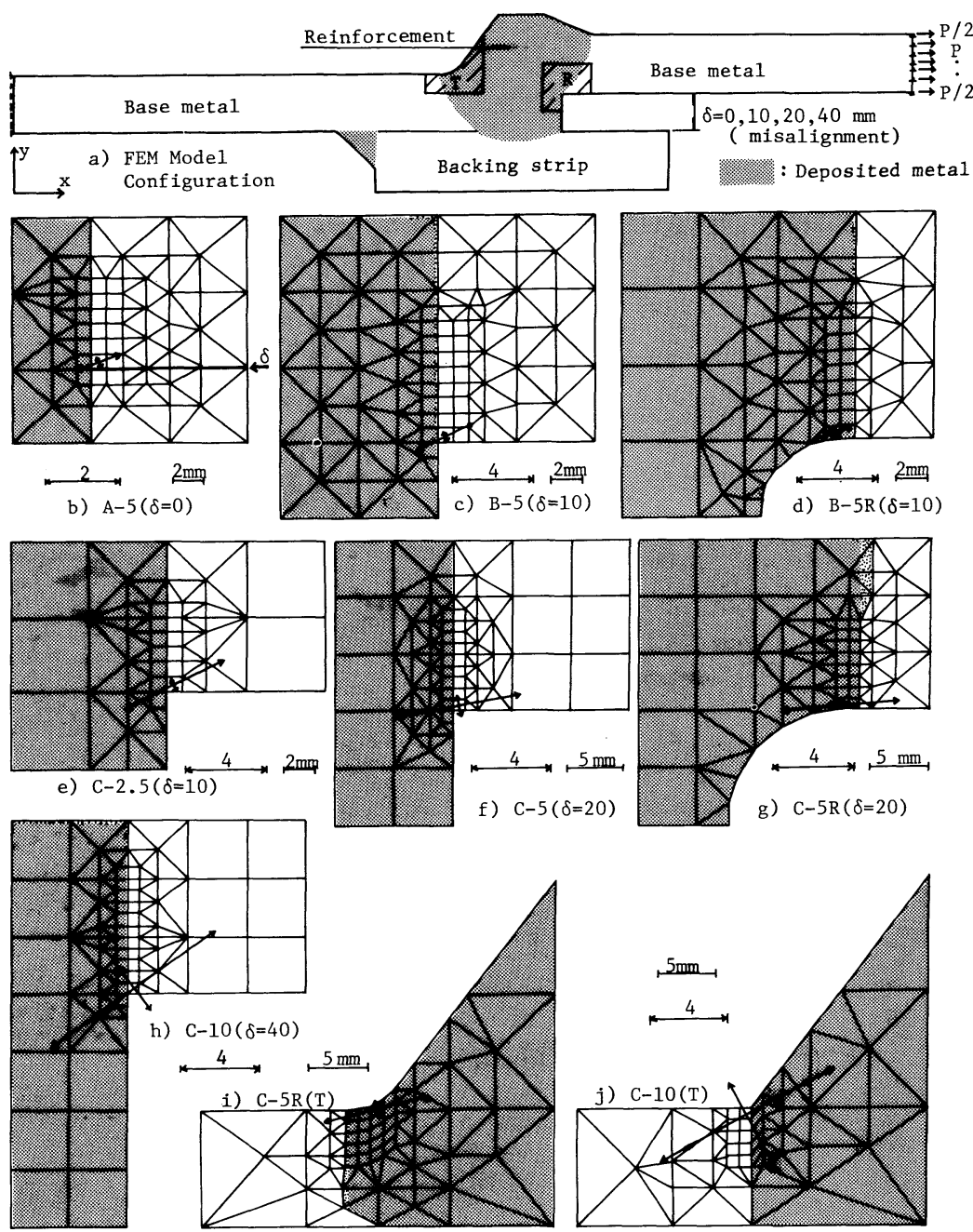

Fig. 2 Stress concentration factor on root and toe of each specimen.

large at deposited metal side in the root of specimen with semi-circular,

2) The SCF of specimen C-10 was large at the toe as well as the root.

\section{STATIC TEST}

The experimental models are as before-mentioned. The materials of all specimens are mild steel of $400 \mathrm{MPa}$ in tensile strength. Slot shown in Fig. 1 was cut by Eletro-discharge Machine. Fig. 3 shows

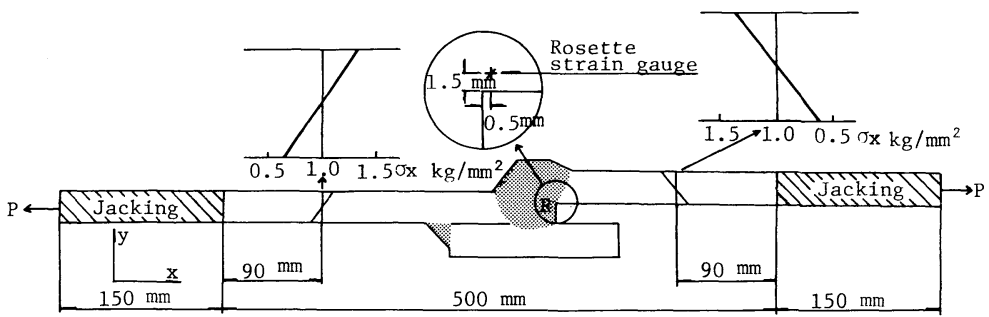

Fig. 3 Stress distribution at parallel portion of specimen C-5. 
stress distribution at parallel portion of specimen $\mathrm{C}-5$ when the nominal stress is unit $\left(1.0 \mathrm{~kg} / \mathrm{mm}^{2}\right)$. From the stress distribution shown in Fig. 3, the specimen is subject to a moment with applied force due to misalignment. Stress concentration factors $\left(\sigma_{X} / \sigma_{n o m}\right.$ and $\left.\sigma_{1} / \sigma_{n o m}\right)$ at the root of each specimen are shown in Fig. 4. Also, the SCF by the finite-element analysis shows in Fig. 4. The stress concentration factors (SCF's) are quantitatively different between the rosette strain gauges and the FEM analysis because the rosette strain gauge can not be attached at edge of specimen. However, the stress concentration factors by the rosette strain gauges and the FEM analysis are qualitatively coincided when misalignment and root radii changed.

\section{FATIGUE TEST}

\section{(1) Experimental procedure}

Specimens were the used tensile test specimens, and crack

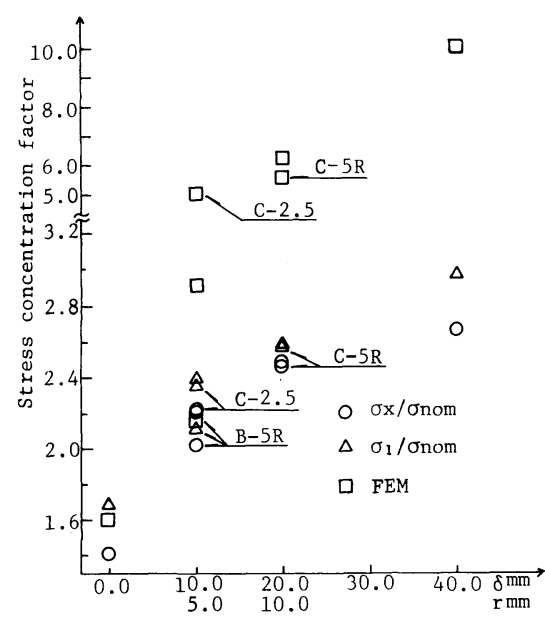

Fig. 4 Stress concentration factor on root for misalignment and root radius.

gauges (pitch $1.0 \mathrm{~mm}$ ) were attached to both sides of specimens instead of rosette strain gauges shown in Fig. 3. The applied stress range was $\Delta \sigma=144 \mathrm{MPa}\left(\sigma_{\max }=162 \mathrm{MPa}, \sigma_{\min }=18.0 \mathrm{MPa}\right)$. Crack propagations were measured and recorded continuously. All tests were carried out under constant stress amplitude of sine wave with servohydraulic testing machine at frequency of $3 \mathrm{~Hz}$.

\section{(2) Test results}

Fractured surface of specimen A-5, B-5, B-5 R, C-5 and C-5 R presented fatigue striation pattern, secondary crack and inter-granular propagation, which are charateristic features of fatigue by constant amplitude cyclic load ${ }^{10)}{ }^{11}$. Crack of specimen $\mathrm{C}-5 \mathrm{R}$ was initiated from the root at first, and then another crack occured at the toe when the first crack propagated up to 3 or $4 \mathrm{~mm}$. Crack of specimen $\mathrm{C}-10$ was initiated from the toe at first, and the striation pattern was not observed, but fibrous pattern was observed on the fractured surface.

The crack propagation behavior of each specimen was shown in Fig. 5. The figure presented crack initiation life $\left(N_{i}\right)$ and fracture life $\left(N_{f}\right)$. Although the moment due to the misalignment occured at both specimen B-5 R and C-5 R, fatigue lives were longer than the specimen A-5 which had not misalignment as shown in Fig. 5. Even though the moment owing to misalignment occured, the fatigue life was improved when the root shape was semicircular.

Fig. 6 shows relation between the fatigue life and the scale-up rate for specimen C-2. 5 and C-5 which had the same root shape. The crack initiation life $\left(N_{i}\right)$ was almost constant, but fracture life $\left(N_{f}\right)$ decreases

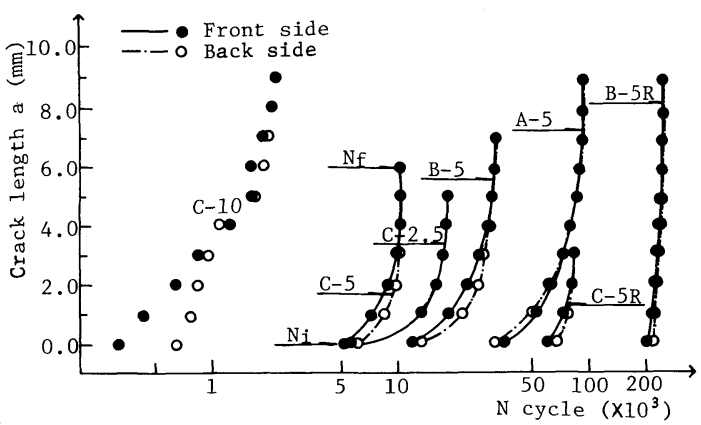

Fig. 5 Crack propagation behavior of each specimen.

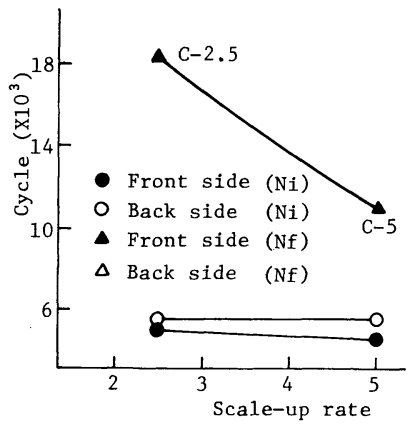

Fig. 6 Relationship between the fatigue life and the scale-up rate. 


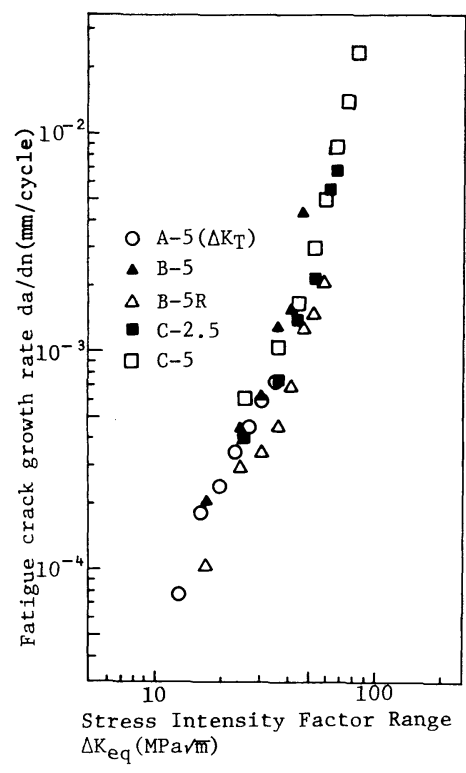

Fig. 7 Relation between $(d a / d n)$ and $\left(\Delta K_{e q}\right)$.

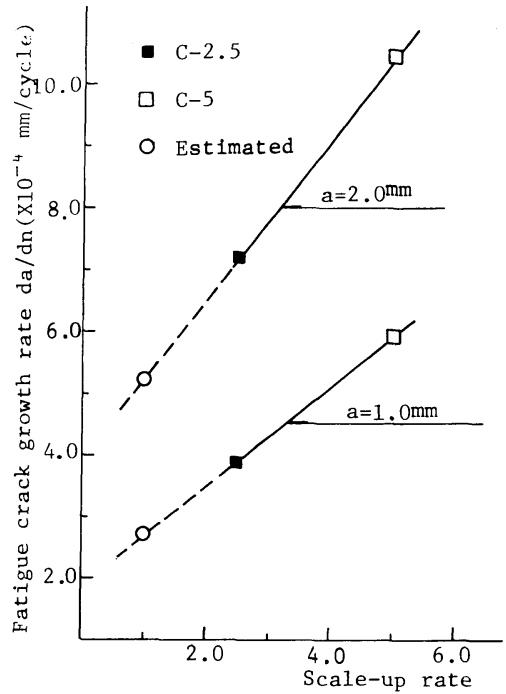

Fig. 8 Relation between $(\mathrm{da} / \mathrm{dn})$ and scale-up rate

from $19 \times 10^{3}$ to $12 \times 10^{3}$ when the scale-up rates are changed from 2.5 to 5 . This means that crack propagation life $\left(N_{p}\right)$ depends upon the scale-up rate.

(3) Discussions on crack propagation

Neglecting the reinforcement and the backing strip shown in Fig. 2 a), the fracture mechanics is applied on fatigue crack growth rate $(d a / d n)$ of each specimen. The stress intensity factor range $\left(\Delta K_{T}\right)$ due to tensile stress $\left(\sigma_{t}\right)$ and the stress intensity factor range $\left(\Delta K_{B}\right)$ due to bending stress $\left(\sigma_{b}\right)$ are given as follows respectively ${ }^{8) .9)}$.

$$
\begin{aligned}
& \Delta K_{T}=\Delta \sigma_{t} \sqrt{\pi a} F(\xi) \\
& \text { where, } F(\xi)=F(a / h) \doteqdot 1.12-0.231 \xi+10.55 \xi^{2}-21.72 \xi^{3}+30.39 \xi^{4} \\
& a: \text { crack length, } h: \text { specimen width } \Delta K_{B}=\Delta \sigma_{b} \sqrt{\pi a} F(\xi)
\end{aligned}
$$

$\Delta K_{e q}=\Delta K_{T}+\Delta K_{B}$

Fig. 7 shows relation between the fatigue crack growth rate $(d a / d n)$ and the stress intensity factor range $\left(\Delta K_{e q}\right)$ of each specimen. This figure shows that $d a / d n \sim \Delta K_{e q}$ relations are rather same even when root shape changed from right angle to semicircular. Fig. 8 shows relationship between the $d a / d n$ and the scale-up rate of specimen C-2.5 and C-5 when crack lengths grew from $1.0 \mathrm{~mm}$ to $2.0 \mathrm{~mm}$. In Fig. 8 , extrapolating the curves to scale-up rate of 1.0 , crack growth rate can be read as $2.7 \times 10^{-4}$ and $5.2 \times 10^{-4}$ respectively.

\section{SUMMARY}

The fatigue strength of welded-joint with misalignment was investigated using the specimen which was scale-up model of a cross section of U-shape trough rib. The stress concentration factor of the root was analyzed by the finite-element method and was measured by static loading test. The cyclic loading test was carried out to clarify the effect of root shape on fatigue life, and the relation between fatigue crack propagation rate and stress intensity factor range. Also, the effect of scale-up rate of the specimen was investigated. The major findings can be summarized as follows:

(1) The SCF was large at base metal side in the root of specimen with right angle, while the SCF was 
large at deposited metal side in the root of specimen with semicircular, and the SCF of specimen C-10 was large at the toe as well as the root.

(2) The stress concentration factors (SCF's) were quantitatively different between the rosette strain gauges and the FEM analysis. However, the stress concentration factors by the rosette strain gauges and the FEM analysis were qualitatively coincided when the misalignment and the root radii changed.

(3) Even though the moment owing to misalignment occured, the fatigue life was improved when the root shape was semicircular.

(4) Extrapolating the curves to scale-up rate of 1.0, the crack growth rate can be read as $2.7 \times 10^{-4}$ and $5.2 \times 10^{-4}$ respectively.

( 5 ) The configuration had to be changed smoothly at the toe as well as the root because the SCF was fairly large, and also the fatigue crack was initiated from the toe.

The fatigue strength of the welded-joint can be improved with smooth root shape as well as toe shape. For this purpose, such welding techniques are considered as changing angle of welding torch, depositing lesser weld metal with lower welding current and using consumables of higher interfacial tension between molten metal and slag.

\section{REFERENCES}

1) Kihara, $\mathrm{H}$. et al. : Effect of notch size, angular distortion and residual stress on brittle fracture initiation characteristics of welding joints for high stength steel (the lst report), Journal of the Society of Naval Architects of Japan, 125, pp. 225 274, 1969.

2) Ito, T., Tanaka, K. and Sato, M. : Effect of plate thickness on brittle fracture initiation from surface notch in weld fusion line, Journal of the Society of Naval Architects of Japan, 131, pp. 335 343, 1972.

3) Akita, Y., Maeda, T. and Yada, T. : On the brittle fracture initiation characteristic to welded structures (2 nd report), Journal of the Society of Naval Architects of Japan, 118, pp. 171 191, 1965.

4) Yada, T. : On brittle fracture initiation characteristic to welded structures ( 3 rd report), Journal of the Society of Naval Architects of Japan, 119, pp. 134 141, 1966.

5) Soya, I. et al. : On the brittle fracture initiation from a surface crack at welded joint, Jorunar of the Society of Naval Architects of Japan, 140, pp. 223 232, 1979.

6) Kondo, A. et al. : Fatigue strength of field-welded trough rib joints of orthotropic steel deck, Proc. of JSCE, No. 340, pp. 49 57, 1983.

7) Horikawa, K., Lee, D. U. and Ishizaki, H. : Fatigue strength of field-welded joints of U-shaped trough rib for bridge deck, Tran. of Japan Welding Research Institute of Osaka University, Vol. 12, No. 2, pp. 127 134, 1983.

8) Paris, P.C. and Erdogen, F. : A critical analysis of crack of propagation laws, Jl. of Basic Engineering, Tran. of ASME, Series D, Vol. 85, No.4, pp. 528 535, 1963.

9) Okamura, H. : Linear fracture mechanics, 1978.

10) Japan Welding Society: Fractographic atlas of steel weldments, pp. 378 437, 1982.

11) Albrecht, P. : A study of fatigue striations in welded toe crack, Fatigue Testing Weldments, ASTM, STP 648, D. W., Hoeppner, Ed., pp. 207 216, 1978.

(Received February 7 1985) 